\title{
Phase Transition of $\mathrm{Fe}_{3} \mathrm{O}_{4}$ Magnetic Material Based on Observation of Curie Temperature and Hysteresis Curve: Micromagnetic Simulation Study
}

\author{
Dewi Azzahra Puspita, Lutfi Rohman, Artoto Arkundato, and Ratna Dewi Syarifah
}

\section{ABSTRACT}

\begin{abstract}
Phase transition yesng happens to the material magnetite $\left(\mathrm{Fe}_{3} \mathrm{O}_{4}\right)$ is an interesting phenomenon to study because it has many important applications, one of which is RAM (Radar Absorbing Material). The magnetic properties of nanomaterials are known to be influenced by their size. In this simulation research, the research objective was to analyze the temperature value of the Curie and the hysteresis curve of the $\mathrm{Fe}_{3} \mathrm{O}_{4}$ material with variations in the size of the material sample cube of $5 \mathrm{~nm}, 8$ $\mathrm{nm}, 10 \mathrm{~nm}, 12 \mathrm{~nm}$, and $15 \mathrm{~nm}$. In this study, using a micromagnetic simulation method based on atomistic models with the Vampire program. The results showed that the Curie temperature value in the $\mathrm{Fe}_{3} \mathrm{O}_{4}$ material was influenced by variations in the size of the material. The Curie temperature values when the side sizes of the cube are $5 \mathrm{~nm}, 8 \mathrm{~nm}, 10 \mathrm{~nm}$, $12 \mathrm{~nm}$, and $15 \mathrm{~nm}$, namely $650 \mathrm{~K}, 635 \mathrm{~K}, 650 \mathrm{~K}, 665 \mathrm{~K}$ and $645 \mathrm{~K}$. The characteristics of the hysteresis curve for $\mathrm{Fe}_{3} \mathrm{O}_{4}$ material based on simulations at each material size $(5 \mathrm{~nm}, 8 \mathrm{~nm}, 10 \mathrm{~nm}, 12 \mathrm{~nm}$, and $15 \mathrm{~nm})$ for several temperatures $(0 \mathrm{~K}, 328 \mathrm{~K}, 473 \mathrm{~K}$ and $773 \mathrm{~K})$ indicate that there is a change in the coercivity and field values. saturation.
\end{abstract}

Keywords: Phase transition, Magnetite, Temperature Curie, Hysteresis Curve.
Published Online: March 23, 2021

ISSN: 2684-4451

DOI :10.24018/ejphysics.2021.3.2.45

\section{A. Puspita *}

Department of Physics, University of Jember, East Java, Indonesia.

(e-mail: dewiazzahrapuspita ${ }^{\circledR}$ gmail.com) L. Rohman *

Department of Physics, University of Jember, East Java, Indonesia.

(e-mail: el_rahman.fmipa@ unej.ac.id)

A. Arkundato

Department of Physics, University of

Jember, East Java, Indonesia.

(e-mail: a.arkundato@unej.ac.id)

R. D. Syarifah

Department of Physics, University of Jember, East Java, Indonesia.

(e-mail: syarifah.physics@ gmail.com)

\section{INTRODUCTION}

Phase transition is a cooperative phenomenon that involves a complete change in the structure and physical properties of a material when an external variable (temperature) is changed continuously. This theory is used to explain ferroelectric, structural, magnetic and even superconducting phase transitions. Usually a phase transition is followed by some symmetric breakdown. For example a magnetic system: at temperatures above the Curie temperature the system has zero magnetization in a zero field or the magnetization does not point in a certain direction. When the temperature is lowered below the Curie temperature, the magnetization spontaneously points in a certain direction. Thus, the directional symmetry in magnetization is broken [1].

Curie temperature is the critical temperature for the ferromagnetic phase transition of a solid material to become paramagnetic due to heating and can be observed with the release of a heated ferromagnetic material from a permanent magnet [2]. The change in state from a ferrimagnetic or ferromagnetic phase to a paramagnetic phase is called a phase transition. This situation occurs only when the characteristic permanent magnet appears below the Curie temperature of about $400{ }^{\circ} \mathrm{C}(673 \mathrm{~K})$ for common ferromagnetic materials such as ferrite or neodymium.
Above this characteristic temperature the spins tend to be random which causes the state to change into a paramagnetic phase [3]. The phase transition changes are influenced by the magnetization and energy values of a magnetic material. The phase transition is influenced by the external magnetic field, the spin of its neighbors, and the resulting interaction strength [4].

Magnetite which has the chemical structure of $\mathrm{Fe}_{3} \mathrm{O}_{4}$ is ferrimagnetic materials have an inverse-spinel cubic structure and are very important ferrimagnetic materials, because from the study of magnetite the theory of ferrimagnetic materials can be understood [5]. In nanoparticle size, magnetite is superpamagnetic, has a high coercivity field value and a low Curie temperature [6]. Supported by other properties, such as its non-toxic (nontoxic) and non-rejection in the body (biocompatible).

In recent years, research on $\mathrm{Fe}_{3} \mathrm{O}_{4}$ has been carried out not only experimentally but also by simulation using the Monte Carlo method approach. The results of the simulation are expected to be used as predictions and optimization of experimental research.There are several applications regarding the $\mathrm{Fe}_{3} \mathrm{O}_{4}$ material, namely as a drug delivery system [7], a lightening agent in MRI (magnetic resonance imaging) [8] and a localizing therapeutic agent in chemotherapy [9]. Magnetite mixed in the material can improve the quality of the material, the biosensor, the 
coating of magnetite mixed with glucose oxide in the biosensor can increase the sensitivity of the sensor and increase its resistivity [10] while liquid magnetite (ferrofluid) added to oil can reduce the temperature and pressure at engine [11].

$\mathrm{Fe}_{3} \mathrm{O}_{4}$ is also an absorbent material for electromagnetic waves which has good magnetic properties, so one of its applications is used asthe basic ingredients for making RAM (Radar Absorbing Material) because it is to dampen reflections or absorb microwaves. RAM is designed as a material that can suppress the reflection of electromagnetic energy on the absorption surface, by removing the electric or magnetic field from the wave into heat with its electrical and dielectric capabilities [12], so that RAM is very good when superimposed on the fuselage, submarines and many tools in the military field so that it is not able to be detected by radars that emit radar waves. Thus it is very useful in the development of national defense technology [13].

Ferrimagnetic is a material in which it is considered to have a magnetic moment belonging to the atoms, so that it has spontaneous magnetization, even in the absence of an external magnetic field. This material has a very large magnetic susceptibility and is temperature dependent. Similar in properties to ferromagnetic materials, if heated above temperature curie, then ferrimagnetic and antiferromagnetic training will turn into paramagnetic materials [14]. Magnetite is an example of the most popular ferrimagnetic material, whereas ferromagnetic which has an anti-parallel magnetic moment pattern below the critical temperature is called anti-ferromagnetic [15], [16].

At room temperature, the magnetite material is ferrimagnetic. As the temperature increases towards the Currie temperature, thermal fluctuations destroy the alignment of the ferromagnetic magnetic moment at the tetrahedral position, so that the ferromagnetic strength decreases. When the Curi temperature is reached, the amount of magnetization becomes zero and superparamagnetic properties are observed [17].

In this study, the researcher wishes to do analysis about studies Curie temperature values, and coercivity fields with variations in size on the material $\mathrm{Fe}_{3} \mathrm{O}_{4}$ uses a Vampire micromagnetic simulation. The Vampire program that runs on the Windows operating system functions to simulate the magnetic properties of a ferromagnetic material atomically, able to determine the magnetic properties of a material such as the temperature curie and the hysteresis curve.Some data will be processed with Origin software and then visualized with Povray software.

The purpose of this study was to determine the effect of side size variations of the cube on differences in the magnetic properties of $\mathrm{Fe}_{3} \mathrm{O}_{4}$ material. The magnetic properties of a material can be determined using the hysteresis curve and temperature curie. The hysteresis curve can provide information about the magnitude of the coercivity field when the magnetization is equal to zero, while the Curie temperature provides information on the critical temperature of the magnetic material. So, in this study, the magnetic properties of $\mathrm{Fe}_{3} \mathrm{O}_{4}$ material based on its hysteresis curve and temperature curie will also be described so that it can be used as a reference or reference in the field of technology.

\section{METHODOLOGY}

The methodology in this research is to conduct a literature review by collecting data sources in the form of books, journals, theses, theses and the internet to obtain material input parameters to be simulated. Furthermore, to support the micromagnetic simulation program, the variables used to determine the magnetic properties of the material are determined. The material used in this research is $\mathrm{Fe}_{3} \mathrm{O}_{4}$ magnetic material. After the simulation process is complete, the results will be obtained in the form of numbers that are visualized in the form of graphs and domain structures in 3 dimensions. The results are then analyzed and concluded according to the problem formulation in this study.

Several micromagnetic simulation programs to simulate the magnetic properties of a material are OOMMF, NMAG and Vampire. In this research, the software used to support the process of implementing the micromagnetic simulation includes the Vampire 4.0 program which is run on the Windows operating system to simulate the magnetic properties of a ferromagnetic material atomically. Before doing the simulation, first prepare an input script containing the characteristics of the magnetic material so that the running program can be run. Then from the simulation results obtained the output file which will be processed with the Origin program. Origin is a software that is used to plot the output files in order to obtain a Curie temperature graph, magnetic susceptibility and material hysteresis curves.

The determination of the coercivity field using a hysteresis curve was carried out by varying the temperature of $0 \mathrm{~K}, 328 \mathrm{~K}, 473 \mathrm{~K}$ and $773 \mathrm{~K}$, for each size of the material given. Then the shape of the material was visualized using the Povray program, and the material properties were analyzed based on the domain structure based on variations in the size of the material. Notepad ++ software, used to edit the preparation of scripts.

TABLE I: DATA TYPES FOR TEMPERATURE SIMULATION

\begin{tabular}{lcc}
\hline \hline Simulation Attributes & Size and Variation & Unit \\
\hline $\begin{array}{l}\text { Particle size } \\
\text { Minimum temperature- } \\
\text { maximum temperature }\end{array}$ & $5,8,10,12$, and 15 & $\mathrm{~nm}$ \\
\hline \hline
\end{tabular}

\begin{tabular}{|c|c|c|c|}
\hline \multicolumn{2}{|c|}{ Simulation Attributes } & \multirow{2}{*}{$\begin{array}{l}\text { Size and Variation } \\
5,8,10,12 \text { and } 15\end{array}$} & \multirow{2}{*}{$\begin{array}{c}\text { Unit } \\
\mathrm{nm}\end{array}$} \\
\hline Particle size & & & \\
\hline \multirow{4}{*}{ Temperature } & Room & 0 & \multirow{4}{*}{$\begin{array}{l}\text { Kelvin, } \\
\text { K }\end{array}$} \\
\hline & Computer operations & 328 & \\
\hline & Overheat & 473 & \\
\hline & $\begin{array}{l}\text { Approaching the Tc } \\
\text { value of the } \mathrm{Fe}_{3} \mathrm{O}_{4} \\
\text { material }\end{array}$ & 773 & \\
\hline
\end{tabular}

The following is a schematic of the research design displayed in the form of a flow chart: 


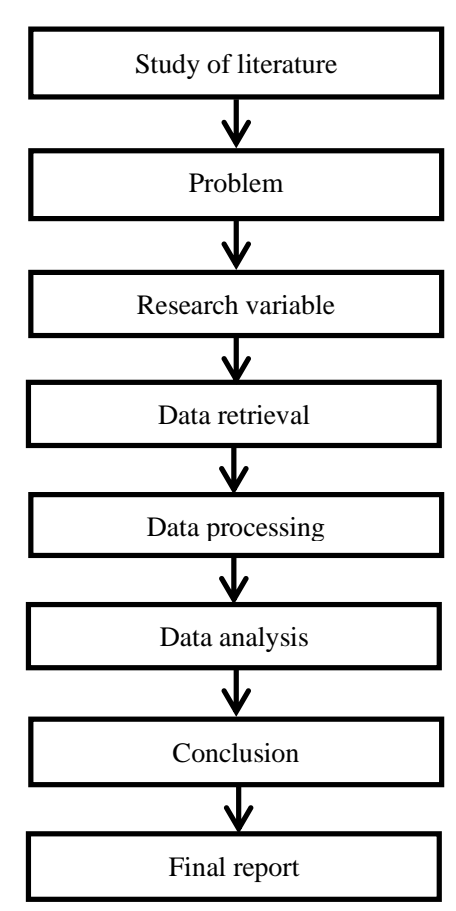

Fig. 1. Flowchart of the research design.

\section{RESUlTS AND DisCUSSION}

\section{A. Curie Temperature}

Symptoms of the transition from the ferrimagnetic phase to the paramagnetic phase can be found in the temperature measurement of the curie for various sizes of $\mathrm{Fe}_{3} \mathrm{O}_{4}$ materials. The value of Tc is obtained by observing the curve showing the change in slope characteristics of the relationship between susceptibility, magnetization and temperature as a result of the emergence of a second-order phase transition from the ferromagnetic phase to the paramagnetic phase.

Research on the Curie temperature was carried out to determine the magnetic properties of a material. The process of determining the Curie temperature is carried out using 5 variations of material sizes, namely $5 \mathrm{~nm}, 8 \mathrm{~nm}, 10 \mathrm{~nm}, 12$ $\mathrm{nm}$, and $15 \mathrm{~nm}$ with a nanocube geometric model. The variation in the size of the side of the cube is used to determine the effect of the change in size on the resulting Curie temperature value, so that the optimum Curie temperature value is obtained from the material $\mathrm{Fe}_{3} \mathrm{O}_{4}$.

The temperature range used is $0 \mathrm{~K}$ to $1000 \mathrm{~K}$ with intervals of $5 \mathrm{~K}$. The change in magnetization with respect to temperature is shown in Fig. 2. To determine the Curie temperature value of a material is done by analyzing the change in magnetization with increasing temperature. Therefore, to determine the temperature of the material Curie, it can be done by looking at the change in magnetization close to zero along with increasing temperature until it becomes constant. When the magnetization approaches zero, the material has reached the limit from the properties of ferromagnetic materials to paramagnetic materials [18].

By observing the curve of Fig. 2 it is clear that the magnetization value of the $\mathrm{Fe}_{3} \mathrm{O}_{4}$ material changes from the ferrimagnetic region at temperatures below $\mathrm{Tc}$ to the paramagnetic region at temperatures above Tc. So, it can be said to experience a change in phase transition from ferrimagnetic to paramagnetic.

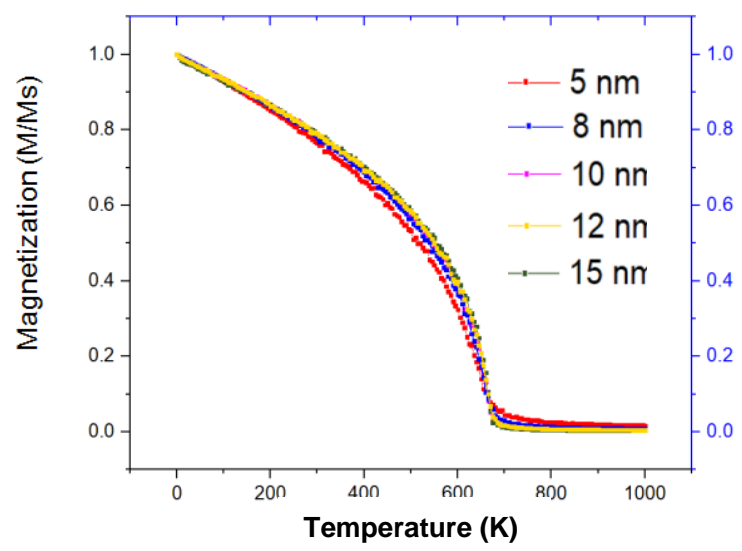

Fig. 2. Graph of the relationshıp between magnetızation and temperature of the $\mathrm{Fe}_{3} \mathrm{O}_{4}$ in the variation of the side size of the nanocube model.

The value of the Curie temperature can be found through graphical analysis of the plotting results of the combined relationship between magnetization and susceptibility to temperature. Combining these graphs is done to obtain a more accurate Curie temperature value, by knowing the highest magnetic susceptibility, the value of the Curie temperature of the material can be determined easily based on the change in magnetization.

Magnetic susceptibility usability can be used to determine the Curie temperature value of a material by considering the highest magnetic susceptibility produced [19]. Fig. 3 is a graph of the determination of Curie temperature based on the change in magnetization and the highest magnetic susceptibility from the results of this study, namely for the size of $15 \mathrm{~nm}$.

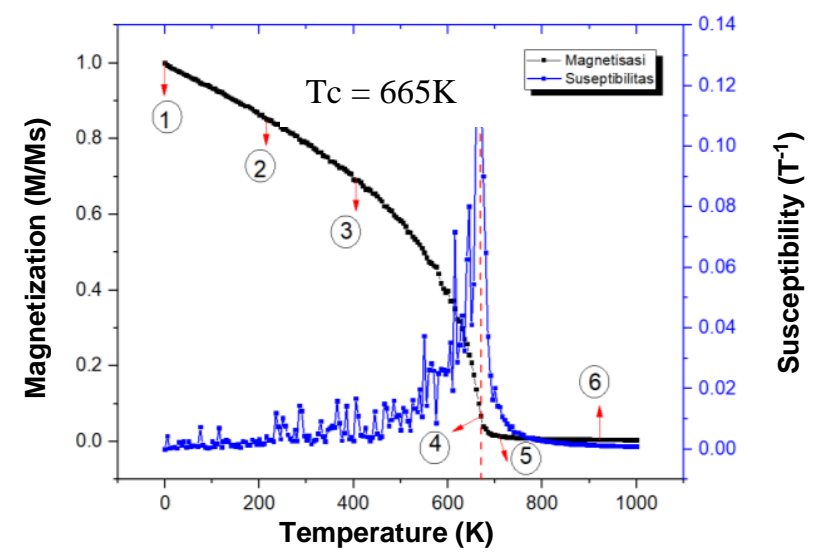

(a)
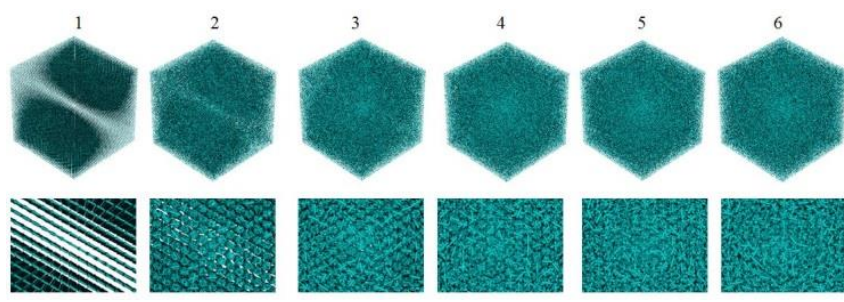

(b)

Fig. 3 (a) Graph of changes in magnetization and temperature susceptibility to $\mathrm{Fe}_{3} \mathrm{O}_{4}$ material at a size of $10 \mathrm{~nm}$,

(b) Visualization of the process of changing the direction of spin in $\mathrm{Fe}_{3} \mathrm{O}_{4}$ material at a size of $10 \mathrm{~nm}$. 
There are two graphs that are interconnected in the Curie temperature determination graph shown in Fig. 3. The black graph is a graph of the relationship between magnetization and temperature, while the graph in blue is a graph of the relationship between magnetic susceptibility to temperature. From this graph, it can be seen that, magnetization decreases with increasing temperature until the magnetization approaches zero and then becomes constant.

Furthermore, in the magnetic susceptibility graph, it can be seen that the highest level of magnetic susceptibility is at the point of magnetization close to zero. This is relevant to the previously described concept that the material is at its Curie temperature point when the magnetization approaches zero and the magnetic susceptibility of the material reaches its maximum point. Through Fig. 3, a connecting line (red line) can be drawn between the highest magnetic susceptibility and near zero magnetization. So that through this connecting line, the Curie temperature of the material can be determined precisely.

A characteristic of a ferrimagnetic material is that its atomic spins are spontaneously polarized in the absence of an external magnetic field applied. This situation occurs when the temperature given does not exceed the Curie temperature. When it exceeds the Curie temperature, the spin orientation of the material will change to random and result in a change in the material from being ferrimagnetic to paramagnetic material. The process of changing the direction of magnetization in $\mathrm{Fe}_{3} \mathrm{O}_{4}$ material at a size of 10 $\mathrm{nm}$ can be seen in Fig. 3 (b) which shows that the spins initially in the same direction will change to random, resulting in a decrease in the value of the magnetization.

The greatest magnetization occurs when the temperature is $0 \mathrm{~K}$, that is, when the spins have a unidirectional orientation (see Fig. 3 (b) point 1). Then in Fig. 3 (b) point 2, the direction of the spin orientation changes slightly due to the increase in temperature, the magnetization value is still large. In Fig. 3 (b) point 3, it shows that the direction of the spin orientation is changing, where the point is approaching the Curie temperature value, which causes the magnetization value to get smaller. In Fig. 3 (b) point 4, the Curie temperature value shows a magnetization state that is close to zero, where the direction of the spin orientation is increasingly random, and begins to show no upward direction. Next in Fig. 3 (b) point 5 and point 6 the direction of the spin has become very random with the addition of temperature (above the Curie temperature value) until the magnetization is close to zero, which indicates that the material has turned into a paramagnetic material. This magnetic transition limit is known as the Curie temperature, which is at point 4 , where the ferromagnetic material before undergoing change into a paramagnetic material. This causes the spin orientation to look more random at temperatures above the Curie temperature value.

Based on the results obtained by observing the magnetization close to zero and the highest susceptibility value, the Curie temperature value of each side size can be seen in Table III.
TABLE III: VALUE OF MATERIAL CURIE TEMPERATURE $\mathrm{FE}_{3} \mathrm{O}_{4}$ NANOCUBE MODEL

\begin{tabular}{ccc} 
& \multicolumn{2}{c}{ NANOCUBE MODEL } \\
\cline { 2 - 3 } $\begin{array}{c}\text { Variation of Side } \\
\text { Size of the Cube } \\
(\mathrm{nm})\end{array}$ & Curie Temperature, Tc (K) \\
\hline 5 & 650 & Reference \\
8 & 635 & \\
10 & 650 & $773-873$ \\
12 & 665 & \\
15 & 645 & \\
\hline \hline
\end{tabular}

Research on phase transition phenomena in ferrimagnetic material $\mathrm{Fe}_{3} \mathrm{O}_{4}$ has been carried out by conducting micromagnetic simulations using the Vampire program. The transition temperature or Curie temperature, Tc of the $\mathrm{Fe}_{3} \mathrm{O}_{4}$ material does not clearly indicate a consistent dependence on material size variations.

\section{B. Hysteresis Curve}

The phase transition of $\mathrm{Fe}_{3} \mathrm{O}_{4}$ magnetic material can be analyzed from its magnetic properties by looking at the hysteresis curve. The properties of magnetite, especially particle size, particle distribution and response to magnetic fields greatly influence the application of magnetite. The data from the simulation results were analyzed using the original software to create hysteresis curves and determine the magnetic quantities of the material, such as saturation magnetization (Ms) and coercivity field (Hc) for each sample.

Analysis of the characteristics of the hysteresis curve is carried out by providing an external field of $-2 \mathrm{~T}$ to $2 \mathrm{~T}$ with a step of changing the magnetic field every $1 \mathrm{~T}$. The hysteresis curve is generated through the process of graphing the change in magnetization to the influence of the external field. The hysteresis curve obtained will be analyzed for the coercivity and saturation fields. The simulation of hysteresis curve determination is carried out at sizes of $5 \mathrm{~nm}, 8 \mathrm{~nm}, 10 \mathrm{~nm}, 12 \mathrm{~nm}$, and $15 \mathrm{~nm}$, with different temperature variations, namely $0 \mathrm{~K}, 328 \mathrm{~K}, 473 \mathrm{~K}$ and $773 \mathrm{~K}$. Temperature variation is used to determine the change in the hysteresis curve by giving different temperatures.

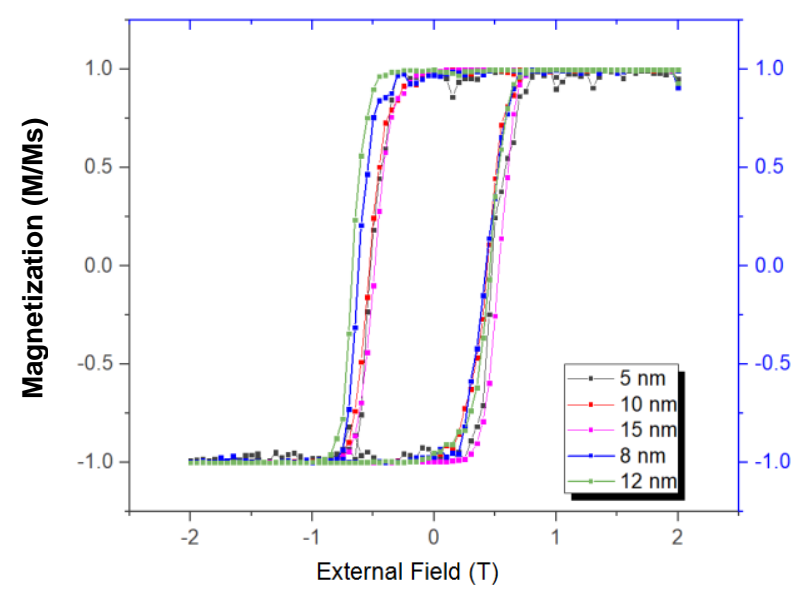

Fig. 4. Hysteresis curve of the material $\mathrm{Fe}_{3} \mathrm{O}_{4}$ with variations in size when the temperature is $328 \mathrm{~K}$.

Based on Fig. 4, it can be seen that the given size variations produce different coercivity field values with the effect of $328 \mathrm{~K}$ temperature. This indicates that the 
difference in material $\mathrm{Fe}_{3} \mathrm{O}_{4}$ size affect the magnitude of the resulting coercivity and saturation field values. The increasing size of the material causes the coercivity field value to increase.

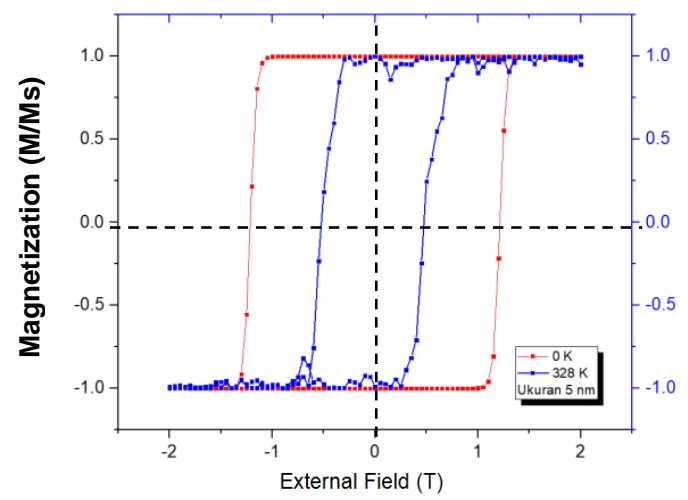

(a)

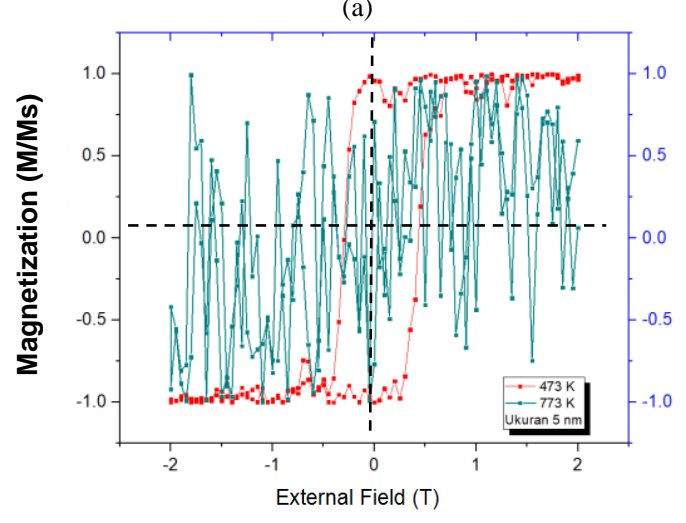

(b)

Fig. 5. Hysteresis curve of $5 \mathrm{~nm}$ size material $\mathrm{Fe}_{3} \mathrm{O}_{4}$ with temperature variations (a) $0 \mathrm{~K}$ and $328 \mathrm{~K}$ (b) $773 \mathrm{~K}$ and $850 \mathrm{~K}$

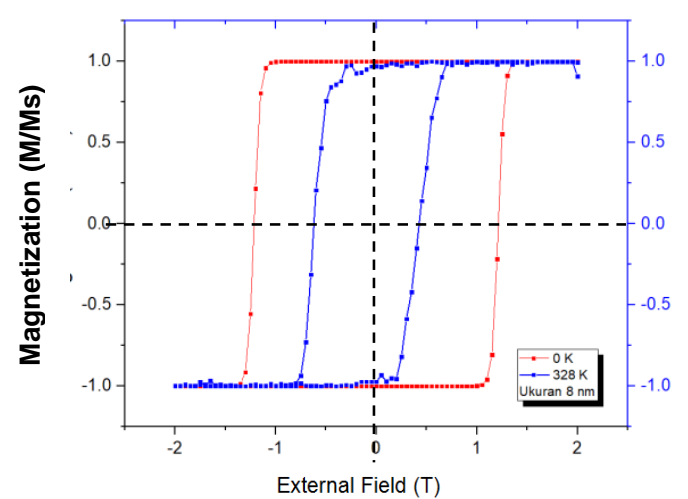

(a)

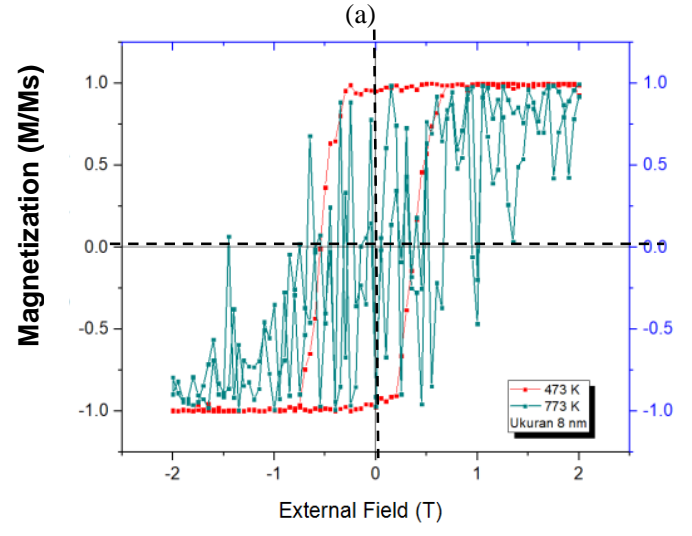

(b)

Fig. 6. Hysteresis curve of $8 \mathrm{~nm}$ material $\mathrm{Fe}_{3} \mathrm{O}_{4}$ with temperature variations (a) $0 \mathrm{~K}$ and $328 \mathrm{~K}$ (b) $773 \mathrm{~K}$ and $850 \mathrm{~K}$

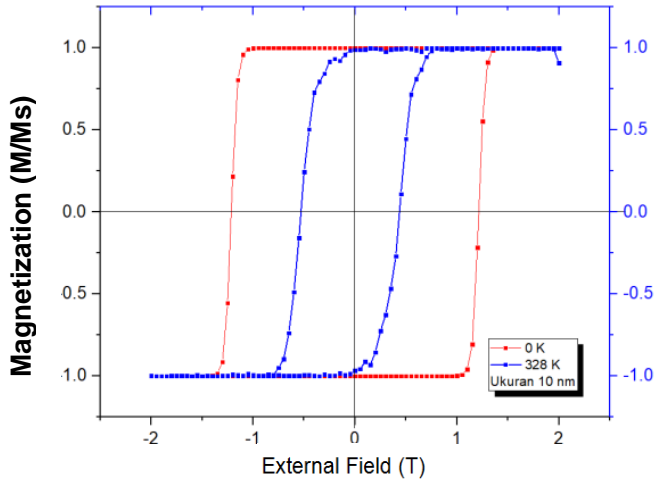

(a)

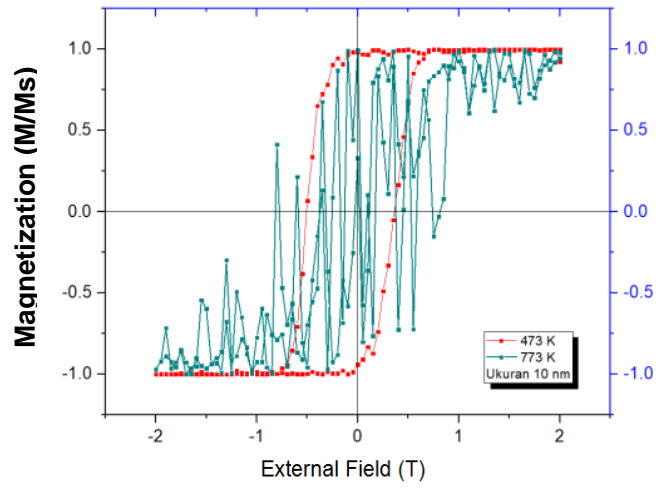

(b)

Fig. 7. Hysteresis curve of $10 \mathrm{~nm}$ size material $\mathrm{Fe}_{3} \mathrm{O}_{4}$ with temperature variations (a) $0 \mathrm{~K}$ and $328 \mathrm{~K}$ (b) $773 \mathrm{~K}$ and $850 \mathrm{~K}$.

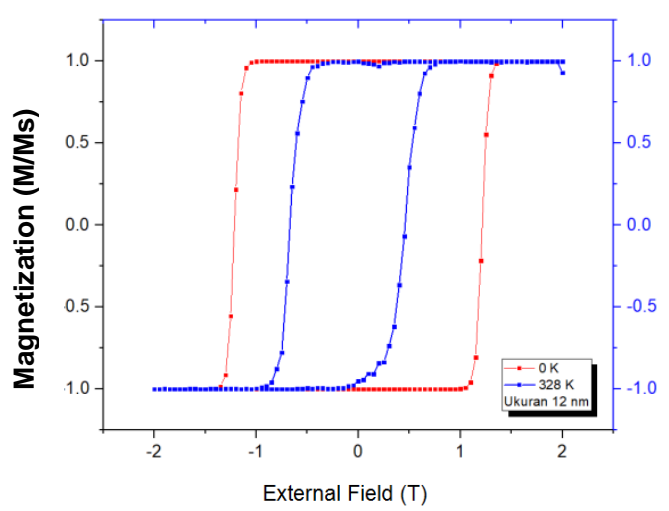

(a)

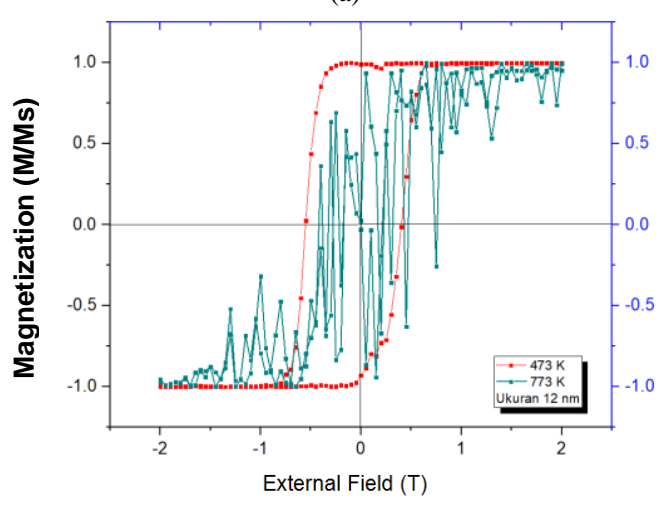

(b)

Fig. 8. Hysteresis curve of $12 \mathrm{~nm}$ size material $\mathrm{Fe}_{3} \mathrm{O}_{4}$ with temperature variations of (a) $0 \mathrm{~K}$ and $328 \mathrm{~K}$ (b) $773 \mathrm{~K}$ and $850 \mathrm{~K}$.

Hysteresis curves with temperature variations are shown in Fig. 5 to Fig. 9, namely when the temperature is below and above the Curie temperature value. The value of the coercivity field $(\mathrm{Hc})$ which changes periodically causes the curve to become full like a hysteresis loop. 


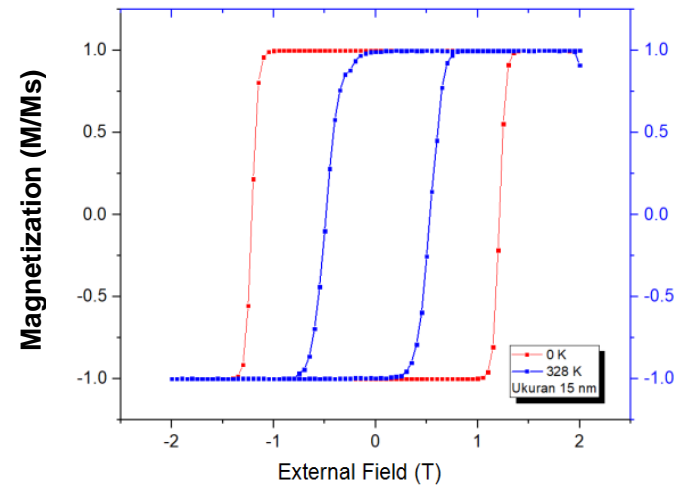

(a)

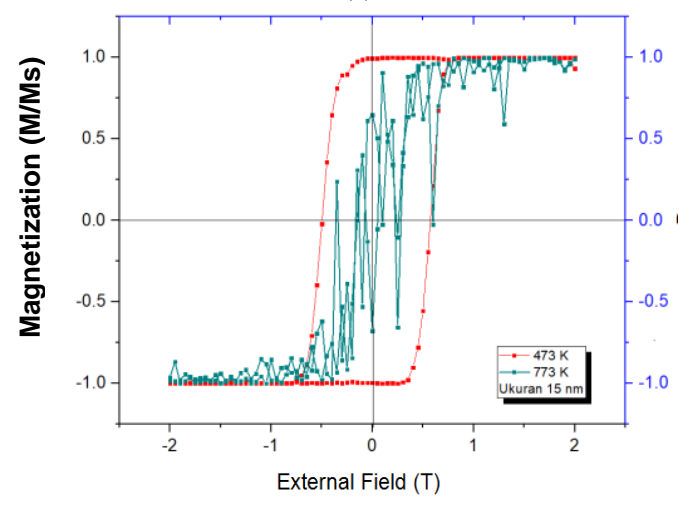

(b)

Fig. 9. Hysteresis curve of $15 \mathrm{~nm}$ size material $\mathrm{Fe}_{3} \mathrm{O}_{4}$ with temperature variations of (a) $0 \mathrm{~K}$ and $328 \mathrm{~K}$ (b) $773 \mathrm{~K}$ and $850 \mathrm{~K}$.

Fig. 5 to 9 show the hysteresis curve when given the temperature variations given to the side sizes of $5 \mathrm{~nm}, 8 \mathrm{~nm}$, $10 \mathrm{~nm}, 12 \mathrm{~nm}$ and $15 \mathrm{~nm}$ cubes. The shape of the resulting hysteresis curve varies with each size variation. As the size of the material $\mathrm{Fe}_{3} \mathrm{O}_{4}$ increases, the coercivity and saturation fields will increase.

The side size of the $5 \mathrm{~nm}$ cube is susceptible to superparamagnetic effects which is indicated by the shape of the hysteresis curve which decreases with increasing temperature. The smaller hysteresis curve indicates that the resulting coercivity and saturation fields are getting smaller. Hysteresis curves in the size range $8 \mathrm{~nm}$ to $12 \mathrm{~nm}$ the values of the coercitivity and saturation fields increase with increasing variations in the size of the sides of the material cube. In the material the highest coercivity and saturation field values are at the size of $12 \mathrm{~nm}$, this indicates that when the size of $12 \mathrm{~nm}$ the material $\mathrm{Fe}_{3} \mathrm{O}_{4}$ still has strong magnetic properties.

At variations in temperature at each material size $\mathrm{Fe}_{3} \mathrm{O}_{4}$ given, affects the coercivity field value of the hysteresis curve that is formed. When the material is given a temperature variation of $0 \mathrm{~K}, 328 \mathrm{~K}, 473 \mathrm{~K}$ and $773 \mathrm{~K}$ the coercivity field value decreases with increasing temperature. This is because the spin orientation is getting more irregular as it approaches the Curiosity temperature, so that the coercivity field of the material will decrease. Even for some conditions the coercivity and saturation fields cannot be determined because the hysteresis curve shape has been damaged, as shown in Fig. 5 to Fig. 9 point (b). The coercivity field values and the material $\mathrm{Fe}_{3} \mathrm{O}_{4}$ saturation fields can be seen in Table IV.
TABLE IV: THE VALUES OF THE COERCIVITY AND SATURATION FIELDS OF THE NANOCUBE MODEL MATERIAL $\mathrm{FE}_{3} \mathrm{O}_{4}$

\begin{tabular}{|c|c|c|c|c|c|c|c|c|}
\hline \multirow{2}{*}{$\begin{array}{c}\text { Variation } \\
\text { in Size } \\
(\mathrm{nm})\end{array}$} & \multicolumn{4}{|c|}{$\begin{array}{l}\text { Coercivity Field (Hc) } \\
(\mathrm{T})\end{array}$} & \multicolumn{4}{|c|}{$\begin{array}{l}\text { Saturation Field (Hs) } \\
(\mathrm{T})\end{array}$} \\
\hline & $0 \mathrm{~K}$ & $328 \mathrm{~K}$ & $473 \mathrm{~K}$ & $\begin{array}{l}773 \mathrm{~K} \\
\end{array}$ & 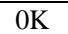 & $328 \mathrm{~K}$ & $473 \mathrm{~K}$ & $773 \mathrm{~K}$ \\
\hline 5 & 1.20 & 0.50 & 0.37 & - & 0.98 & 0.96 & 0.95 & - \\
\hline 8 & 1.20 & 0.52 & 0.45 & - & 0.98 & 0.99 & 0.99 & - \\
\hline 10 & 1.20 & 0.45 & 0.42 & - & 0.98 & 0.98 & 0.94 & - \\
\hline 12 & 1.20 & 0.55 & 0.47 & - & 0.98 & 0.98 & 0.98 & - \\
\hline 15 & 1.20 & 0.52 & 0.52 & - & 0.98 & 0.97 & 0.96 & - \\
\hline
\end{tabular}

The theoretical tendency of decreasing the saturation magnetization value occurs because in this range the value its total magnetic moment has also decreased. This coercivity value is also influenced by grain and crystal size, where when the value of the crystal size increases, the coercivity field decreases, which indicates that the magnetic properties of the material decrease due to the non-uniform direction of the high magnetic dipole moment [20], and vice versa. The greater the coercivity field value, the stronger and better the magnetic properties of the material are [21].

The change in magnetization occurs due to the influence of the external field on the ferromagnetic material. The change in spin direction during the magnetization process of magnetic materials can be affected by the external field and temperature. Fig. 10 and Fig. 11 show the process of changing the magnetization of the material $\mathrm{Fe}_{3} \mathrm{O}_{4}$, the size of $5 \mathrm{~nm}$ at $0 \mathrm{~K}$ and $328 \mathrm{~K}$ temperatures. The process of changing the magnetization observed on the hysteresis curve is 10 points, starting from the positive saturation magnetization to returning to that point forming a cycle.

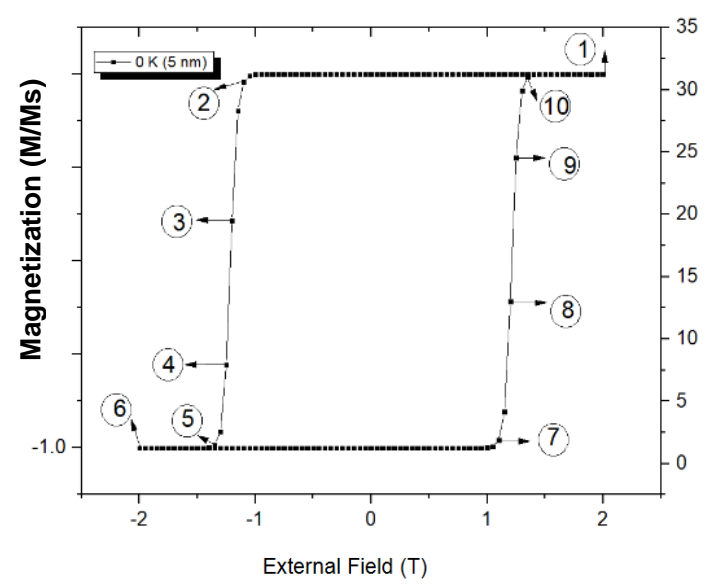

(a)

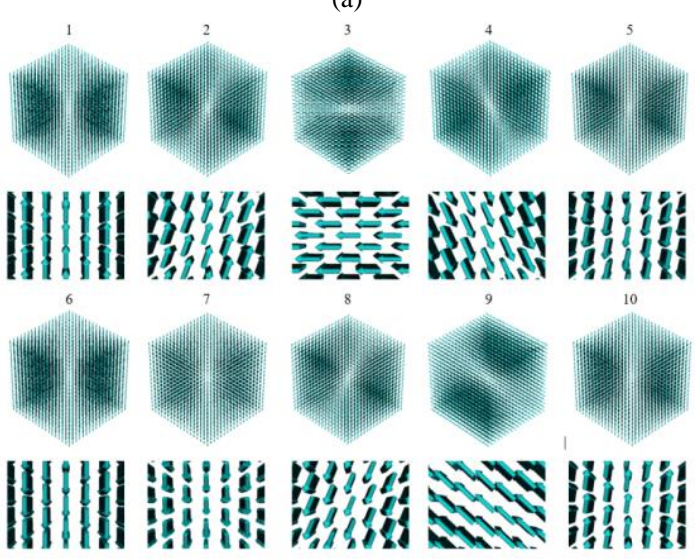

(b)

Fig. 10. Changes in the direction of magnetization to the external field of the $\mathrm{Fe}_{3} \mathrm{O}_{4}$ material at $0 \mathrm{~K}$ temperature of $5 \mathrm{~nm}$ nanocube geometry. 
Fig. 10 shows the process of changing the hysteresis curve magnetization in the material $\mathrm{Fe}_{3} \mathrm{O}_{4}$, size of $5 \mathrm{~nm}$ at $0 \mathrm{~K}$ temperature, the spin orientation tends to be homogeneous. This is because the hysteresis curve is not influenced by temperature. Starting from point 1 , where the direction of the spin orientation is still in the same direction, namely upward (spin-up). When the external field decreases, there is a change in the magnetization of the material. Point 2 is the limit where the magnetization decreases slightly and the direction of the spin orientation begins to change slightly. At point 3 and point 4 it shows that the direction of the spin orientation is getting more random and the spin does not point upward anymore because the external field is decreasing. At point 5 is the state of magnetization of the material $\mathrm{Fe}_{3} \mathrm{O}_{4}$, begins to move in the opposite direction at the first point to the 6 th point where the spin direction of the atom points downward. Then at the 7 th point the magnetization began to increase again as the external field increased. The increasing magnetization can be seen at point 8 and point 9 where the spin direction starts to move in the opposite direction to point 3 and point 4 . However, the value of the external field at point 8 and point 9 moves towards the positive $\mathrm{x}$-axis, while at point 3 and point 4 previously the external field moves towards the negative $\mathrm{x}$-axis. Until the 10th point, which is a state where the external magnetic field value of the material is $\mathrm{Fe}_{3} \mathrm{O}_{4}$, start back up like in point 1 .
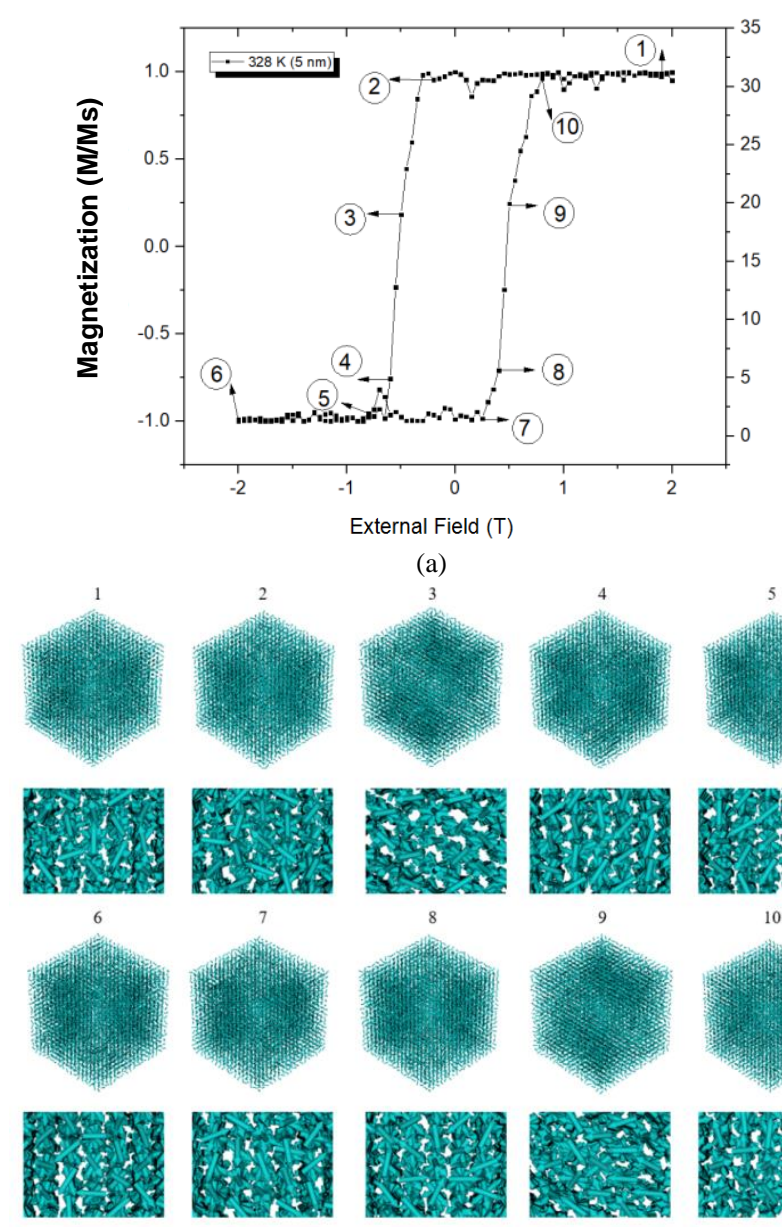

(a)
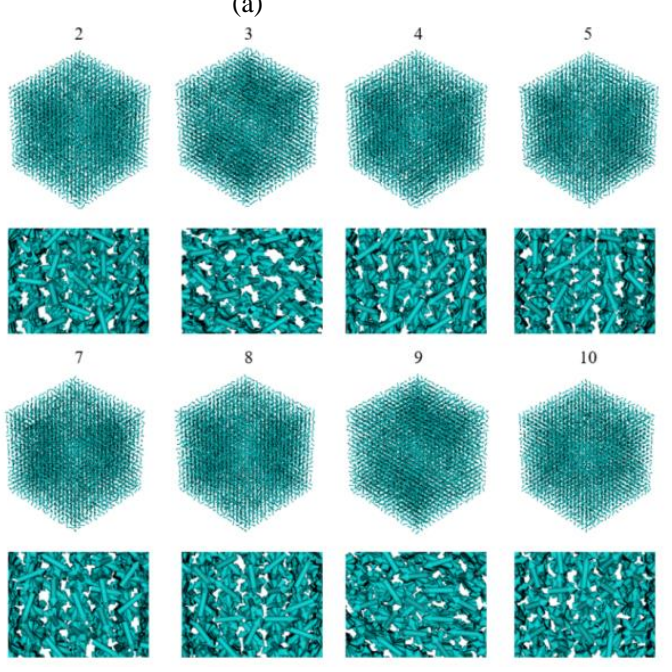

10
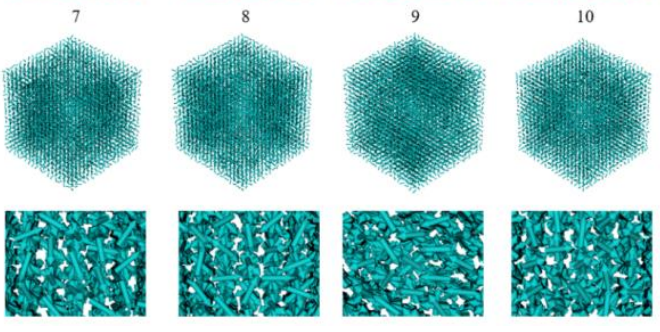

(b)

Fig. 11. Changes in the direction of magnetization to the external field of the $\mathrm{Fe}_{3} \mathrm{O}_{4}$ material at a temperature of $328 \mathrm{~K}$ size $5 \mathrm{~nm}$ nanocube geometry.
Fig. 11 is the hysteresis curve of the material $\mathrm{Fe}_{3} \mathrm{O}_{4}$, at $328 \mathrm{~K}$. Starting from point 1 , the $\mathrm{x}$-axis direction is positive, where magnetization has an atomic spin orientation that tends to be shifted, which is upward dominant. When the external field is reduced there is a change in the magnetization of the material $\mathrm{Fe}_{3} \mathrm{O}_{4}$. The second point is the limit of the magnetization state before it changes and the magnetization decreases but the direction of the spin orientation tends to remain the same. Point 3 and point 4 are a state of magnetization that begins to change marked by the direction of the spin orientation that changes to the right. The 5th point is a state when the magnetization changes the direction of the spin orientation downward. Point 6 is the opposite of point 1 on the negative $\mathrm{X}$-axis. This is indicated by the downward orientation. The 8th point and the 9th point of magnetization have changed again, which is the opposite of the 3rd and 4th points which are marked by the direction of the spin orientation that is no longer downward but changes direction tending to the left.

\section{CONCLUSION}

Variation in the size of the sides of the cube in the material $\mathrm{Fe}_{3} \mathrm{O}_{4}$, based on simulation resultslooks affect the value of the Curie temperature and hysteresis curve test material. Curie temperature values for materials $\mathrm{Fe}_{3} \mathrm{O}_{4}$, at sizes $5 \mathrm{~nm}, 8 \mathrm{~nm}, 10 \mathrm{~nm}, 12 \mathrm{~nm}$ and $15 \mathrm{~nm}$ are $650 \mathrm{~K}$, $635 \mathrm{~K}, 650 \mathrm{~K}, 665 \mathrm{~K}$ and $645 \mathrm{~K}$.

The results of the analysis show that the $\mathrm{Fe}_{3} \mathrm{O}_{4}$ material undergoes a phase transition and structure from being ferimagnetic to paramagnetic at a temperature of $773 \mathrm{~K}$ for all material size variations.

\section{ACKNOWLEDGMENT}

The authors would like to thank to the LP2M University of Jember for financial support of the research through the Hibah Keris Batch 1 year 2020.

\section{REFERENCES}

[1] UNY, Yogyakarta State University. (2013). Landau's Theory of Phase Transitions. [Online]. Available: http://staffnew.uny.ac.id/upload/132206562/lainlain/TEORI+TENTA NG+TRANSISI+FASE.pdf.

[2] RO Okimustava, "Determination of the temperature of the iron curie using the electric wire method"In Physics Seminar and Its Applications 2009 | vol: | issue: | 2009.

[3] K. Fabian, VP Shcherbakov and SA McEnroe, "Measuring the Curie temperature"presented at the AGU and the Geochemical Society, Volume 14, Number 4, doi: 10.1029 / 2012GC004440, ISSN: 15252027, 24 April 2013.

[4] Ahda, NV, Alatas, H. and Hardhienata, H. (2018). Magnetization of Solids Using an Insulating Model with Spatial Variation of Magnetic Fields. IPB.http://repository.ipb.ac.id/handle/123456789/93707.

[5] BD Cullity, CD Graham, Introduction to Magnetic Materials (2nd Edition, Wiley and Sons. Inc, 2008).

[6] JMD Coey, Magnetism and Magnetic Materials (Cambridge University Press, New York, 2009).

[7] Q. Li, et al., Exp Therm Fluid Sci, 30, 109 (2005).

[8] JQ Cao, et al., J. Magn Magn Mate, 277, 165 (2004).

[9] A. Jordan, et al., J. Magn Magn Mate, 194, 185 (1999).

[10] BW Lu, WC Chen, J.Magn Magn Mate, 304, e400 (2006).

[11] YS Kim, YH Kim, J. Magn Magn Mate, 267, 105 (2003). 
[12] Wang, Y., T. Li, L. Zhao, Z. Hu, and Y. Gu, "Research Progress on Nanostructured Radar Absorbing Materials. Energy Power Eng 3: 580-584, 2011.

[13] D. Ristiani and M. Zainuri, "Design of Double-Layer Radar Absorbing Materials with the Dallenbach Layer Method Based on Natural Magnetic Materials, Ocean Soil and Polyaniline," ITS Journal of Science and Arts, vol. 5 No. 2 (2016) 2337-3520 (2301-928X Print).

[14] Yelfianhar, I. (2010). Magnetic Material. Accessed fromhttps://iwan78.files.wordpress.com.

[15] ASM, Metal handbook, vol 10, Material characterization, The American Society for Metal, Metal Park, Ohio, 1992.

[16] Tauxe, L., Paleomagnetic Principles, and Practice. Kluwer Academic Publishers, 1998.

[17] Blaney, Lee. 2007. Magnetite (Fe3O4): Properties, Synthesis, and Applications. Lehigh Review, paper 5 Volume 15.

[18] Arifin, S., "Study of Magnetic Properties of Co (1-X) Ni (X) Random Alloy and Double Layers Ferromagnetic Materials in Various Co and Ni Composition of Materials", 2016.

[19] Evans, RFL, and A. Biternas. 2014. Vampire User manual: Software Version 4.0. York: The University of York, York, YO10 5DD:

[20] Mashuri, 2012. "Nano Ni0,5Zn0,5Fe2O4 particles made from raw materials $\mathrm{Fe} 3 \mathrm{O} 4$ from Iron Sand as a Perforating Material Microwaves at High Frequency. " Dissertation Physics Department Doctoral Program, Faculty of Mathematics and Natural Sciences ITS in 2012.

[21] Sun, S., CB Murray, D. Weller, L. Folks, and AJ s. Moser. 2000. Monodisperse FePt nanoparticles and ferromagnetic FePt nanocrystal superlattices. 287 (5460): 1989-1992.

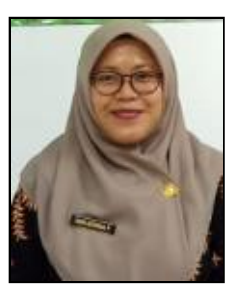

Dewi Azzahra Puspita Born in Malang, June 5, 1993. A bachelor's degree in physics (S. Si) in the field of interest in biophysics from the University of Jember was obtained in 2016. A bachelor's degree in education (S. Pd) in physics education was obtained in 2018 from the Open University.

Has worked as a non-permanent teacher for Physics since 2012 at SMA Plus Al Azhar Jember and in 2019 was accepted as a PNS Teacher teaching science at MTs Negeri 1 Jember.

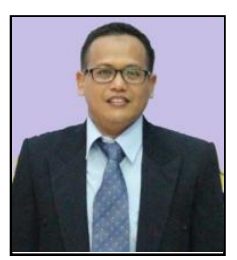

Lutfi Rohman born in the city of Demak, August 20, 1972. A bachelor's degree (S. Si) in physics was obtained from the Bogor Agricultural Institute in 1995, a master's degree (M. Si) in applied pure physics in 2004 from the University of Indonesia, and the title Dr. from the University of Indonesia in 2014 in the field of Material Science. His research interest is computation of magnetic materials.

Now working as a lecturer in the Department of Physics, Faculty of Mathematics and Natural Sciences, Jember University. Subjects being taught are statistical physics, solid matter physics, computational physics and material computation.

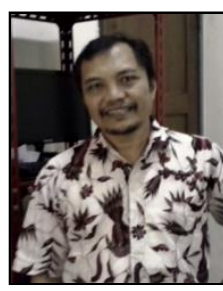

Artoto Arkundato born on December 25, 1969. A bachelor's degree ( $\mathrm{S}$. Si) in physics was obtained from Gadjah Mada University in 1995, a master's degree (M.Si) was obtained in 2003 from the Bandung Institute of Technology (ITB), and the title Dr. from the Bandung Institute of Technology (ITB) in 2012. His research field of interest is material computing, especially molecular dynamics computing.

Currently working as a lecturer in the Department of Physics, Faculty of Mathematics and Natural Sciences, Jember University, teaching courses in nuclear physics, quantum physics, computational physics and molecular dynamics computation.

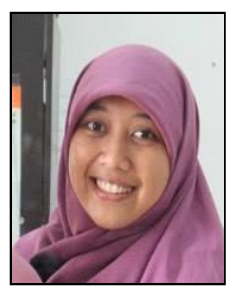

Ratna Dewi Syarifah born March 20, 1988. Has a bachelor's degree in physics education (S. Pd) from Semarang State University in 2010, a master's degree (M. Si) in nuclear physics in 2014 from the Bandung Institute of Technology (ITB) and the University of d'Aix-Marseille, and a degree doctoral from the Bandung Institute of Technology in 2018 in the field of nuclear physics. His research interests are reactor physics, particularly the design and model of "gas cooled fast reactors".

Working as a lecturer in the Department of Physics, Faculty of Mathematics and Natural Sciences, Jember University. Subjects being taught are modern physics, introduction to core physics and basic physics. 